\title{
High inter-observer reliability in standardized ultrasound measurements of subcutaneous adipose tissue in children aged three to six years
}

\author{
A. Kelso ${ }^{1}$, W. Müller ${ }^{2 *}$, A. Fürhapter-Rieger ${ }^{2}$, M. Sengeis ${ }^{2}$, H. Ahammer ${ }^{2}$ and J. M. Steinacker ${ }^{1}$
}

\begin{abstract}
Background: A procedure to measure subcutaneous adipose (SAT) using brightness-mode ultrasound has recently been standardized and applied to various groups of adults including underweight, overweight and obese adults. High reliability of this procedure was found in each of the examined groups. The purpose of this study was to determine inter-observer reliability of the standardized brightness-mode ultrasound measurement of uncompressed SAT in three to six-year-old children.

Methods: Three experienced observers independently captured the ultrasound images at the eight standardized measurement sites in each of the 20 children and evaluated their images using an interactive software that detects the SAT contour and automatically measures multiple thicknesses in each image; the mean of these represents SAT thickness at a given site. The children were aged $4.9 \pm 1.0$ years; their body mass index ranged from 13.6-17.7 $\mathrm{kgm}^{-2}$. Sound speed was set to $1450 \mathrm{~ms}^{-1}$ for SAT.

Results: SAT thickness sums with fibrous structures included $\left(D_{1}\right)$ ranged from 25.7-86.4 mm, mean $D_{1}$ was $48.1 \pm 15.5 \mathrm{~mm}$. For $D_{1}$, resulting from 160 measurements by each observer, the intra-class correlation coefficient was 0.998 (95\% confidence interval 0.980-0.999), standard error of the estimate was $1.1 \mathrm{~mm}$, and $95 \%$ limits of agreement were within $\pm 2.1 \mathrm{~mm}$. The median difference in $D_{1}$ was $0.8 \mathrm{~mm}$, i.e. about $1.9 \%$ of mean $D_{1}$.

Conclusions: Inter-observer results in children are comparable to previously described high reliability in adults. This method, which provides a technical thickness measurement accuracy of about 0.1 to $0.2 \mathrm{~mm}$, enables monitoring of subcutaneous adipose tissue in children with a similarly high reliability as was obtained in adults previously.

Trial registration: German Institute of Medical Documentation and Information, German Clinical Trials Register (DRKS) ID: DRKS00010089; Date 24/02/2016.
\end{abstract}

Keywords: Body composition, Body fat, Ultrasound imaging, Preschool children, Precision

* Correspondence: wolframmueller@medunigrazat

${ }^{2}$ Institute of Biophysics, Medical University of Graz, Neue Stiftingtalstraße 6,

8010 Graz, Graz, Austria

Full list of author information is available at the end of the article

(c) The Author(s). 2020 Open Access This article is licensed under a Creative Commons Attribution 4.0 International License, which permits use, sharing, adaptation, distribution and reproduction in any medium or format, as long as you give appropriate credit to the original author(s) and the source, provide a link to the Creative Commons licence, and indicate if changes were made. The images or other third party material in this article are included in the article's Creative Commons licence, unless indicated otherwise in a credit line to the material. If material is not included in the article's Creative Commons licence and your intended use is not permitted by statutory regulation or exceeds the permitted use, you will need to obtain permission directly from the copyright holder. To view a copy of this licence, visit http://creativecommons.org/licenses/by/4.0/. The Creative Commons Public Domain Dedication waiver (http://creativecommons.org/publicdomain/zero/1.0/) applies to the data made available in this article, unless otherwise stated in a credit line to the data. 


\section{Background}

Body composition and growth are important determinants of childhood health [1]. Although childhood overweight and obesity is associated with serious health problems and the risk of premature illness and death later in life, prevalence rates continue to increase [2, 3]. The United Nations International Children's Emergency Fund, the World Health Organization (WHO) and the World Bank Group recently published updated estimates on the nutrition status in children under five years of age [3]: in 2017, 38 million children worldwide were estimated to be overweight; at the same time, $7.5 \%$ of children around the globe were effected by wasting (i.e., approximately 50 million children were too thin for their height) [3].

These estimates were derived from measurements of body mass and height and compared to normative growth standards [1-3].

In addition to the analysis of body height $(h)$ and body mass $(m)$, there are several other anthropometric measures in use for determining relative body weight and body composition in adults and in children [1, 4-6]. Many epidemiological studies focus on indices such as the body mass index (BMI) $\left(m / h^{2}\right)[2,7-9]$, which is a measure of relative body weight, but not a useful tool for determining the individual's body composition because it cannot distinguish between body fat and muscle mass $[1,4]$. A similar BMI in different individuals may not correspond to a similar amount of body fat. Furthermore, as stated by the WHO Expert Committee: 'Problems in using the BMI further arise in individuals whose shape differs from the norm, particularly in individuals whose legs are shorter or longer than might be expected for their height' [5]. As an alternative measure for relative body weight, the mass index $\mathrm{MI}=0.53 \mathrm{~m} /(h \cdot \mathrm{s})$ has been proposed, which considers the individual's sitting height $(s)$ and thus, implicitly, the leg length [10-12]. Nonetheless, both BMI and MI measure relative body weight and are not useful for determining body fat content $[4,13]$.

A widely used approach for assessing body fat, specifically subcutaneous adipose tissue (SAT), is the measurement of skinfolds. Skinfold thickness is composed of a double fold of compressed adipose tissue and skin [14]. Skinfold measurement is a low-cost method of regional body fat assessment, but has inherent methodological shortcomings. Errors in the collection of raw skinfold data are expected due to site-specific compression of adipose tissue and individual variations in the elasticity of the skin $[15,16]$. Additionally, researchers and practitioners should be wary of prediction equations that estimate total body fat percentage from skinfolds on the individual level $[1,14]$. The accuracy and validity of these equations relies on several assumptions: skinfolds are of constant compressibility, skin thickness is the same at all sites, fat fraction and patterning of SAT are constant, as is the ratio of external to internal adiposity. As stated by Marfell-Jones et al. and by Clarys et al.: 'none of these assumptions hold true' [14, 15]. These shortcomings explain the large discrepancies between skinfold and ultrasound (US) measurements [17].

A new approach has recently been introduced which results in highly accurateand reliable measurements of uncompressed SAT in adults [15, 18]. This approach captures the skin, SAT, muscle fascia and the underlying muscle tissue using a standardized ultrasound imaging and image evaluation procedure at eight clearly defined body sites [19, 20]. When the appropriate speed of sound for the given tissue is used to determine the distance between borders, the measurement accuracy for determining tissue borders is approximately $0.1-0.2 \mathrm{~mm}$ at $12-18 \mathrm{MHz}$ probe frequency $[12,15,19]$. The reliability of this technique has been tested previously in various study populations $[12,18-20]$. Determining inter-observer reliability in lean individuals and physically well-trained athletes with sums of SAT thicknesses including embedded fibrous structures $\left(D_{\mathrm{I}}\right)$ ranging from $D_{\mathrm{I}}=10$ to $50 \mathrm{~mm}$, $95 \%$ of the values among experienced observers were found to be within $\pm 1.0 \mathrm{~mm}$ from the mean [19]. In a group of lean to obese adults with $D_{\text {I }}$ ranging from 12 to $245 \mathrm{~mm}, 95 \%$ of repeated observer measurements were within $\pm 2.2 \mathrm{~mm}$ from the mean [20]. In a subgroup with $D_{\text {I }}$ ranging from 12 to $77 \mathrm{~mm}, 95 \%$ of values were within \pm $1.4 \mathrm{~mm}$ from the mean, and in a second subgroup with $D_{\mathrm{I}}$ ranging from 53 to $245 \mathrm{~mm}, 95 \%$ of values were within \pm $2.9 \mathrm{~mm}$ from the mean [20].

In a sample of 274 preschool children, mean SAT thickness significantly differed between boys and girls, while anthropometric characteristics such as body mass, body height, BMI, and waist circumference did not show any significant differences [21]. Additionally, when a subset of 16 children was measured twice by one observer and $D_{\mathrm{I}}$ was compared, the intra-class correlation coefficient (ICC $=0.994)$ and its 95\% confidence interval (95\% CI: 0.983-0.998) indicated excellent intra-observer reliability [21]. Thickness sums $D_{\text {I }}$ ranged from 34.8 to $112.3 \mathrm{~mm}, 95 \%$ of measurement differences in $D_{\text {I }}$ were within 0.4 to $2.0 \mathrm{~mm}$ [21].

The standardized ultrasound technique for measuring SAT has repeatedly shown high intra-and inter-observer reliability in various groups of adults [18-20], and high intra-observer reliability in children [21].

However, inter-observer reliability studies in children are missing. The aim of this study was to bridge this gap and to compare the results found in preschool children aged three to six years to the published results in adult groups. The analysis of the inter-observer reliability will allow a large-scale implementation of this technique. 


\section{Methods}

\section{Participants and observers}

In the Health Survey, an evaluation study of the preschool-based health promotion program Join the Healthy Boat in Southwest Germany, ultrasound measurements of SAT were performed as part of body composition analysis [21, 22]. The inter-observer reliability analysis presented here took place within the framework of the evaluation study, for which an additional preschool was recruited. The Health Survey was registered at the German Clinical Trials Register (DRKS) operated by the German Institute of Medical Documentation and Information, Cologne, Germany (ID: DRKS00010089) and approved by the ethics committee of Ulm University (application number 188/15) and is in accordance with the Declaration of Helsinki. Written consent to participate in the reliability analysis was given by the parents of 20 children ( $40 \%$ boys) aged $4.9 \pm 1.0$ years. Three observers (AF, AK, MS) certified by the International Association of Sciences in Medicine and Sports (www.iasms.org) performed the ultrasound measurements of SAT (Fig. 1a). The three observers had previously measured over 300 individuals using the standardized ultrasound approach [19]. The sites were marked on the right side of the body (Fig. 1b) by one of the observers and double-checked by one of the other two observers. Each of the three observers captured the eight ultrasound images of each of the 20 children and evaluated these 160 images, without having access to the results of the other two observers. The example of one such measurement series is shown in Fig. 1c.

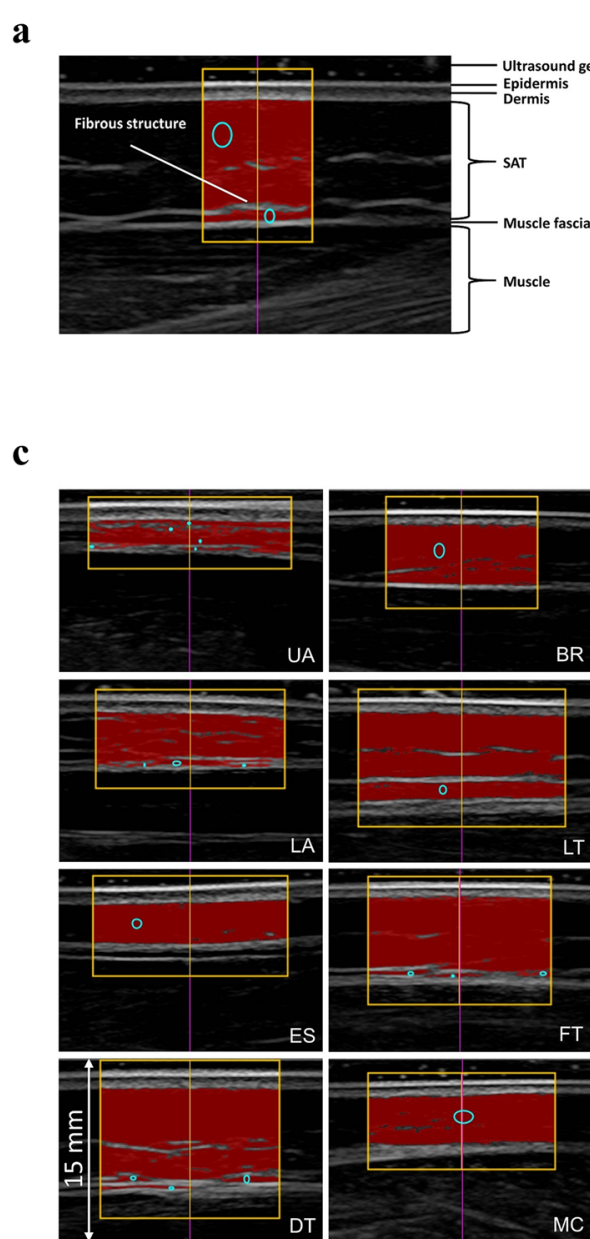

\section{b}
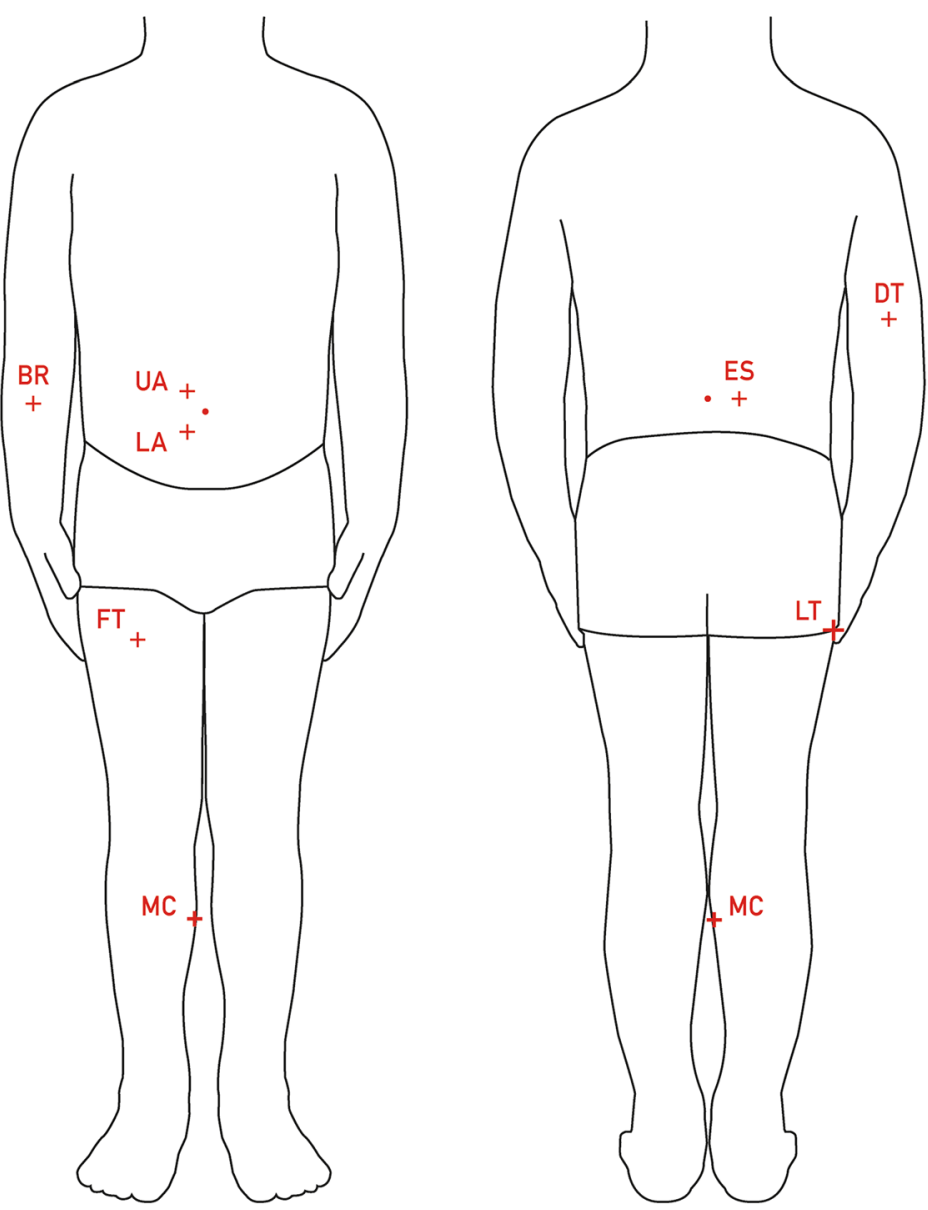

Fig. 1 Brightness-mode ultrasound imaging of SAT. a Example of an ultrasound image taken at the site distal triceps. Within the region of interest, the software evaluation algorithm automatically measured subcutaneous adipose tissue thickness (SAT) along 118 vertical lines from the lower border of the dermis to the upper border of the muscle fascia. Mean SAT thickness $(d)$ including embedded fibrous structures $\left(d_{1}\right)$ was 8.1 $\mathrm{mm}$, excluding embedded structures $\left(d_{\mathrm{F}}\right)$, SAT thickness was $7.5 \mathrm{~mm}$. b Ultrasound measurement sites: upper abdomen (UA), lower abdomen $(L A)$, erector spinae (ES), distal triceps (DT), brachioradialis (BR), lateral thigh (LT), front thigh (FT), medial calf (MC). c Series of evaluated ultrasound images: image depth was $30 \mathrm{~mm}$, sum of SAT thicknesses at the eight sites including embedded structures $\left(D_{1}\right)$ was $36.1 \mathrm{~mm}\left(D_{\mathrm{E}}=33.0 \mathrm{~mm}\right)$. Thicknesses of individual sites $d_{1}\left(d_{\mathrm{E}}\right.$ in parentheses) at UA: $2.1 \mathrm{~mm}(1.6 \mathrm{~mm}), \mathrm{LA}: 3.8 \mathrm{~mm}(3.4 \mathrm{~mm}), \mathrm{ES}: 2.9 \mathrm{~mm}(2.9 \mathrm{~mm}), \mathrm{DT}: 7.2 \mathrm{~mm}(6.4 \mathrm{~mm}), \mathrm{BR}$ : $4.4 \mathrm{~mm}(4.2 \mathrm{~mm}), \mathrm{LT}: 6.3 \mathrm{~mm}(5.5 \mathrm{~mm}), \mathrm{FT}: 5.9 \mathrm{~mm}(5.5 \mathrm{~mm}), \mathrm{MC} 3.5 \mathrm{~mm}(3.5 \mathrm{~mm})$ 


\section{Anthropometry}

Anthropometric measurements were performed in accordance with the International Standards for Anthropometric Measurements [23]. Body height (h), sitting height $(s)$ were measured to the nearest $0.1 \mathrm{~cm}$, and body mass $(m)$ to the nearest $0.05 \mathrm{~kg}$. The BMI $\left(m / h^{2}\right)$ and the MI $(0.53 \mathrm{~m} /(h \cdot s))[4,11,12]$ were calculated. The MI considers individual sitting height $s$ for assessing relative body weight. In individuals with long legs, the MI is higher than the BMI and vice versa. For a person with a Cormic index $C=s / h=0.53$, representing mean leg length, the BMI and the MI are equal $[4,11,12]$.

\section{Site marking}

The observers marked the eight standard sites on the right side of the participants' body. These sites are defined with respect to the individual's body height $(h)$ [19]. In this group of children, the same percentages defined in adults were used without modifications. Fig. 1b shows the eight standard sites. The upper abdomen, lower abdomen, and lateral thigh were marked with the participant standing; the erector spinae was marked in an upright sitting position; distal triceps, brachioradialis were marked with the forearm supported by a table and the upper arm positioned vertically; front thigh and medial calf were marked with the foot supported such that the upper leg was positioned horizontally. The detailed description and illustration of the site marking has been published previously [19].

\section{Ultrasound}

Three observers captured the brightness-mode ultrasound images at the eight marked measurement sites in each child independently and evaluated their 160 images. The standardized brightness-mode ultrasound imaging was performed with the participants lying in a supine, prone or rotated position [19]. The operator positioned the centre of the linear probe over the marked site and held it perpendicularly to the skin and longitudinally in the direction of the underlying muscle.

A thick layer of ultrasound gel, typically $5 \mathrm{~mm}$, was used between the probe and the skin to avoid compression. The gel layer appeared as a black band on top of the ultrasound image, and underneath, the epidermis, dermis, SAT, muscle fascia, and muscle were clearly visible (Fig. 1a and c). The ultrasound systems used by the observers (CX50 Philips Ultrasound, Bothell, WA, USA; GE Logiq-e General Electric, GE Healthcare, IL, USA) with linear probes operated at 12 to $18 \mathrm{MHz}$ had similar image resolution of 0.1 to 0.2 $\mathrm{mm}$. The accuracy obtainable with brightness-mode (Bmode) ultrasound depends on the probe frequency, on the appropriate setting of the ultrasound system, and on the skills of the observer. Linear probes were used for quantitative measurements. Tissue compression was avoided by including a thick layer of gel between the probe and the skin $[12,15,19]$. The resolution of ultrasound imaging is determined by the ultrasound wavelength $(\lambda)$ : at $18 \mathrm{MHz}$ probe frequency (f), a resolution of about $0.1 \mathrm{~mm}$ can be obtained, which is approximately equal to the wavelength. A detailed discussions of the ultrasound thickness measurement accuracy can be found in preceding publications [12, 19, 20].

Each of the three observers captured the eight images at the standardized sites in 20 children, resulting in three measurement series and a number of $3 \cdot 8 \cdot 20=480$ ultrasound images, which formed the basis for this interobserver reliability study.

\section{Image evaluation}

The images were imported into the SAT image evaluation software (NISOS-FAT v 3.2, Rotosport, Stattegg, Austria; www.rotosport.at) to evaluate SAT thicknesses at the eight standard sites. The observers evaluated their sets of images independently. The SAT contour was detected interactively, and multiple thicknesses of SAT, typically 100 per image, were measured automatically. The robust mean of these thicknesses determines the SAT thickness at the given site. Speed of sound was set to $c=1450 \mathrm{~ms}^{-1}$ for distance determination in SAT [24]. The semi-automatic tissue segmentation of the software was controlled visually. The software reported thickness values at each individual site $(d)$ including and excluding embedded fibrous structures (indices I and E, respectively), and also calculated the sums of the eight individual sites $D_{\mathrm{I}}$ and $D_{\mathrm{E}}$, respectively. The sum of embedded fibrous structures was also calculated as $D_{\mathrm{I}}-D_{\mathrm{E}}$.

\section{Statistical analysis}

SPSS 21 (IBM Corp, Armonk, NY, USA) was used. Values were reported as mean \pm standard deviation (SD). Normal distribution was tested using the Shapiro-Wilk test. The ICC and its' 95\% CI were calculated based on a two-way random effects model with average measures [25]. A linear regression analysis was performed to calculate the standard error of the estimate when comparing the individual measurement results of the three observers to their mean values; additionally, Pearson's product-moment correlation coefficient $r$ was determined. The level of significance was set to $p \leq 0.05$. Modified Bland-Altman plots were constructed to display the individual observer differences $(\Delta)$ from their mean $\left(D_{\text {MEAN }}\right)$, and $95 \%$ limits of agreement were calculated as mean difference \pm 1.96 .SD of the differences [26]. Similar types of data agreement between multiple observers have previously been used by Jones et al. [27], and in a series of reliability studies of the ultrasound method in various groups of adults [12, 15, 18-20]. ANOVA including Levene statistics for variance homogeneity and Tukey- 
HSD post hoc tests was carried out to test inter-observer homogeneity.

\section{Results}

In this group of children, mean SAT thickness sums including embedded fibrous structures ( $\left.D_{\mathrm{I}, \mathrm{MEAN}}\right)$, calculated from three measurement series per child, ranged from 25.7 to $86.4 \mathrm{~mm}$ (Table 1); the group mean value was $48.1 \pm 15.5 \mathrm{~mm}$. The thickness sums excluding embedded structures, $D_{\mathrm{E}, \mathrm{MEAN}}$, ranged from 21.4 to 80.5 $\mathrm{mm}$, with a group mean of $43.4 \pm 15.0 \mathrm{~mm}$ (Table 1). Table 2 shows the $D_{\mathrm{I}}$-values of each observer and for each participant. In addition, each observer's individual difference, $\Delta_{\mathrm{I}}$, from $D_{\mathrm{I}, \mathrm{MEAN}}$ is given. The respective values for $D_{\mathrm{E}}$ can be found in Additional file 1 .

Figure 2a shows the $D_{\mathrm{I}}$-values measured by the three observers plotted against $D_{\mathrm{I}, \mathrm{MEAN}}$ for each of the 20 participants. The ICC was 0.998 (95\% CI: 0.980-0.999), the standard error of the estimate was $1.1 \mathrm{~mm}$, and Pearson's $r$ was 0.997 . The inter-observer results for $D_{\mathrm{E}}$ were: $\mathrm{ICC}=$ 0.998 (95\% CI: 0.995-0.999), standard error of the estimate $=1.0 \mathrm{~mm}$, and Pearson's $r=0.998$ (Fig. 2b).

The individual observer differences $\Delta_{\mathrm{I}}$ from $D_{\mathrm{I}, \mathrm{MEAN}}$ are plotted in Fig. 3a. The SD of observer differences from $D_{\mathrm{I}, \mathrm{MEAN}}$ was $1.1 \mathrm{~mm}, 95 \%$ limits of agreement were $\pm 2.1 \mathrm{~mm}$ (1.96.SD). Accordingly for $D_{\mathrm{E}}: \mathrm{SD}=1.0$ $\mathrm{mm}, 95 \%$ limits of agreement were $\pm 2.0 \mathrm{~mm}$ (Fig. 3b). Variance homogeneity (Levene test) was given with $p=$ 0.985 . ANOVA yielded no differences between observers with $p=0.904$ and post hoc tests (Tukey-HSD) $p>0.895$.

Table 1 Characteristics of the study sample $(n=20)$

\begin{tabular}{llll}
\hline & MEAN \pm SD & $($ range $)$ & Unit \\
\hline Age & $4.86 \pm 0.96$ & $(3.10-6.36)$ & {$[$ year $]$} \\
Height, $h$ & $1.09 \pm 0.1$ & $(1.0-1.3)$ & {$[\mathrm{m}]$} \\
Sitting height, $s$ & $0.61 \pm 0.04$ & $(0.57-0.71)$ & {$[\mathrm{m}]$} \\
Mass, $m$ & $18.5 \pm 3.9$ & $(13.5-29.1)$ & {$[\mathrm{kg}]$} \\
Body mass index, BMI & $15.4 \pm 1.2$ & $(13.6-17.7)$ & {$\left[\mathrm{kgm}^{-2}\right]$} \\
Mass index, MI & $14.5 \pm 1.2$ & $(12.5-17.1)$ & {$\left[\mathrm{kgm}^{-2}\right]$} \\
Cormic index, $C$ & $56.3 \pm 1.2$ & $(53.7-59.2)$ & {$[1]$} \\
$D_{1}$ OBS 1 & $47.0 \pm 15.2$ & $(24.9-84.6)$ & {$[\mathrm{mm}]$} \\
$D_{1}$ OBS 2 & $48.0 \pm 15.3$ & $(25.3-85.8)$ & {$[\mathrm{mm}]$} \\
$D_{1}$ OBS 3 & $49.2 \pm 15.8$ & $(26.9-88.9)$ & {$[\mathrm{mm}]$} \\
$D_{\text {I,MEAN }}$ & $48.1 \pm 15.5$ & $(25.7-86.4)$ & {$[\mathrm{mm}]$} \\
$D_{E}$ OBS 1 & $42.9 \pm 15.1$ & $(21.0-79.7)$ & {$[\mathrm{mm}]$} \\
$D_{E}$ OBS 2 & $43.8 \pm 15.4$ & $(21.3-81.1)$ & {$[\mathrm{mm}]$} \\
$D_{E}$ OBS 3 & $43.7 \pm 14.6$ & $(21.7-80.7)$ & {$[\mathrm{mm}]$} \\
$D_{\text {E,MEAN }}$ & $43.4 \pm 15.0$ & $(21.4-80.5)$ & {$[\mathrm{mm}]$} \\
\hline
\end{tabular}

$D_{1}$ sum of subcutaneous adipose tissue of the eight measured sites including embedded fibrous structures, $D_{\mathrm{E}}$ sum of subcutaneous adipose tissue excluding embedded fibrous structures, $O B S$ observer, $S D$ standard deviation
Table 2 SAT thickness sums of each participant measured by the three observers

\begin{tabular}{|c|c|c|c|c|c|c|c|}
\hline \multirow[b]{2}{*}{ P } & \multirow[b]{2}{*}{$D_{I, \text { MEAN }}$} & \multicolumn{3}{|c|}{$D_{1}[\mathrm{~mm}]$} & \multicolumn{3}{|c|}{$\Delta_{l}[\mathrm{~mm}]$} \\
\hline & & OBS1 & OBS2 & OBS3 & OBS1 & OBS2 & OBS3 \\
\hline 1 & 25.7 & 24.9 & 25.3 & 26.9 & -0.8 & -0.4 & 1.2 \\
\hline 2 & 32.4 & 31.6 & 32.1 & 33.4 & -0.8 & -0.3 & 1.0 \\
\hline 3 & 32.4 & 30.9 & 33.2 & 33.0 & -1.5 & 0.8 & 0.6 \\
\hline 4 & 36.7 & 36.2 & 36.5 & 37.3 & -0.5 & -0.2 & 0.6 \\
\hline 5 & 37.1 & 36.2 & 36.4 & 38.7 & -0.9 & -0.7 & 1.6 \\
\hline 6 & 38.0 & 37.1 & 38.8 & 38.0 & -0.9 & 0.8 & 0.0 \\
\hline 7 & 39.2 & 38.2 & 39.7 & 39.8 & -1.0 & 0.5 & 0.6 \\
\hline 8 & 39.9 & 38.0 & 40.9 & 40.8 & -1.9 & 1.0 & 0.9 \\
\hline 9 & 40.2 & 39.8 & 40.1 & 40.6 & -0.4 & -0.1 & 0.4 \\
\hline 10 & 43.5 & 42.8 & 42.9 & 44.8 & -0.7 & -0.6 & 1.3 \\
\hline 11 & 44.8 & 43.1 & 45.3 & 45.9 & -1.7 & 0.5 & 1.1 \\
\hline 12 & 48.7 & 47.9 & 48.4 & 50.0 & -0.8 & -0.3 & 1.3 \\
\hline 13 & 52.6 & 52.3 & 51.9 & 53.6 & -0.3 & -0.7 & 1.0 \\
\hline 14 & 52.7 & 50.5 & 53.0 & 54.5 & -2.2 & 0.3 & 1.8 \\
\hline 15 & 52.9 & 52.7 & 52.4 & 53.6 & -0.2 & -0.5 & 0.7 \\
\hline 16 & 53.4 & 53.2 & 52.0 & 55.0 & -0.2 & -1.4 & 1.6 \\
\hline 17 & 61.2 & 59.7 & 61.5 & 62.4 & -1.5 & 0.3 & 1.2 \\
\hline 18 & 64.9 & 63.7 & 65.1 & 65.9 & -1.2 & 0.2 & 1.0 \\
\hline 19 & 78.5 & 76.5 & 78.4 & 80.7 & -2.0 & -0.1 & 2.2 \\
\hline 20 & 86.4 & 84.6 & 85.8 & 88.9 & -1.8 & -0.6 & 2.5 \\
\hline
\end{tabular}

Individual thickness sums of subcutaneous adipose tissue (SAT) including embedded fibrous structures $\left(D_{1}\right)$ for each of the 20 participants $(P)$ and for each of the three observers (OBS), and and the means of the three measurements $\left(D_{I, \text { MEAN }}\right)$. Individual observer differences from the mean were calculated as: $\Delta_{1}=D_{1}-D_{1, \text { MEAN }}$

Absolute values of observer differences ABS $\left(\Delta_{\mathrm{I}}\right)$ from $D_{\mathrm{I}}$, MEAN ranged from 0.0 to $2.5 \mathrm{~mm}$, the median was $0.8 \mathrm{~mm}$. ABS $\left(\Delta_{E}\right)$ also ranged from 0.0 to $2.5 \mathrm{~mm}$, and the median was $0.7 \mathrm{~mm}$. The relative measurement differences from the mean of the three observations were calculated as: $\Delta_{\text {rel }}=100 \cdot \operatorname{ABS}(\Delta) / D_{\text {MEAN }}$. For $D_{\mathrm{I}}$, the median of the relative differences $\Delta_{\mathrm{I}, \text { rel }}$ was $1.9 \%$, the maximum $4.7 \%$; for $D_{\mathrm{E}}$ median $\Delta_{\mathrm{E}, \text { rel }}$ was $2.1 \%$, and the maximum $5.5 \%$.

Figure 4a shows absolute values of observer deviations from their mean $\mathrm{ABS}\left(\delta_{\mathrm{I}}\right)$ at the eight individual sites $(n=3 \cdot 20=60)$, Fig. $4 \mathrm{~b}$ shows $\mathrm{ABS}\left(\delta_{\mathrm{E}}\right)$. Median values of $\mathrm{ABS}\left(\delta_{\mathrm{I}}\right)$ ranged from 0.1 to $0.3 \mathrm{~mm}$, maximum deviation was $1.6 \mathrm{~mm}$. Median values of ABS $\left(\delta_{\mathrm{E}}\right)$ ranged from 0.1 to $0.4 \mathrm{~mm}$, maximum deviation was $1.7 \mathrm{~mm}$ [see Additional file 2].

The BMI values ranged from 13.6 to $17.7 \mathrm{kgm}^{-2}$ (Table 1); Table 3 compares each participant's $D_{\mathrm{I}}$ value to the BMI. Pearson's $r$ was $0.78(p<0.01)$. Although the BMI range covered only about four units, the highest $D_{\mathrm{I}}$-value, $D_{\mathrm{I}}=86.4 \mathrm{~mm}$, was 3.4 times larger than the lowest $D_{\mathrm{I}}$-value, $D_{\mathrm{I}}=25.7 \mathrm{~mm}$. In several cases, almost 

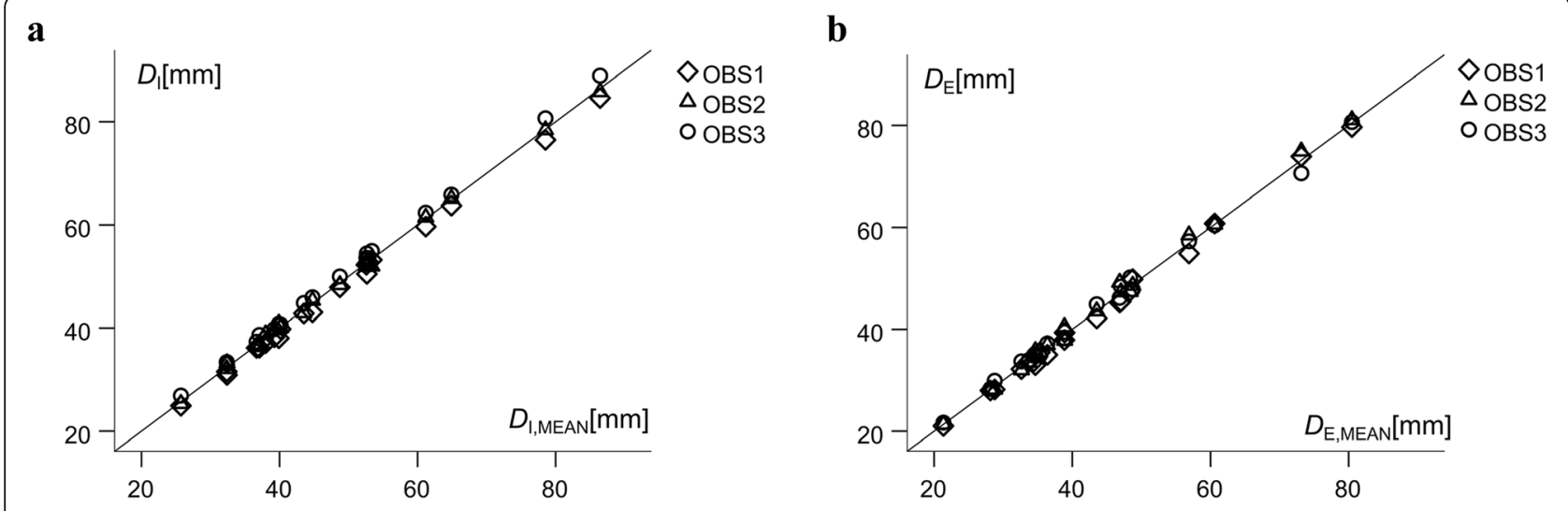

Fig. 2 SAT thickness sums from eight sites measured three times in each of the 20 participants. a SAT thickness sums including embedded fibrous structures $\left(D_{1}\right)$ plotted against the mean value of the three observers. Pearson's correlation coefficient $r=0.997$, standard error of the estimate $(\mathrm{SEE})=1.1 \mathrm{~mm}$, and intra-class correlation coefficient $(\mathrm{ICC})=0.998$ (95\% Cl: 0.980-0.999). b SAT thickness sums excluding embedded fibrous structures $\left(D_{\mathrm{E}}\right) . r=0.998 ; \mathrm{SEE}=1.02 ; \mathrm{ICC}=0.998(95 \% \mathrm{Cl}=0.995-0.999)$

the same BMI values were associated with large differences in $D_{\mathrm{I}}$, e.g. individuals with a BMI of $15.3 \mathrm{kgm}^{-2}$, $15.4 \mathrm{kgm}^{-2}$, and $15.7 \mathrm{kgm}^{-2}$ showed sums of SAT thicknesses of $32.4 \mathrm{~mm}, 52.6 \mathrm{~mm}$, and $61.2 \mathrm{~mm}$, respectively.

Table 3 also shows the Cormic indices of the children and the improved measure for relative body weight MI, which considers the individual's leg length. All MI values were lower than the BMI values, indicating shorter leg lengths of children when compared to adults. For randomized groups of Caucasian adults, the mean BMI is equal to the mean MI $[4,12]$.

\section{Discussion}

This inter-observer study conducted by three observers (of two research centers) in 20 children aged three to six years resulted in a SEE of $1.1 \mathrm{~mm}$, and the $95 \%$ limits of agreement were within $\pm 2.1 \mathrm{~mm}$. The ICC was 0.998 (95\% CI $0.980-0.999)$, and the median difference in $D_{\mathrm{I}}$ a $\diamond$ OBS1 $\triangle$ OBS2 O OBS3

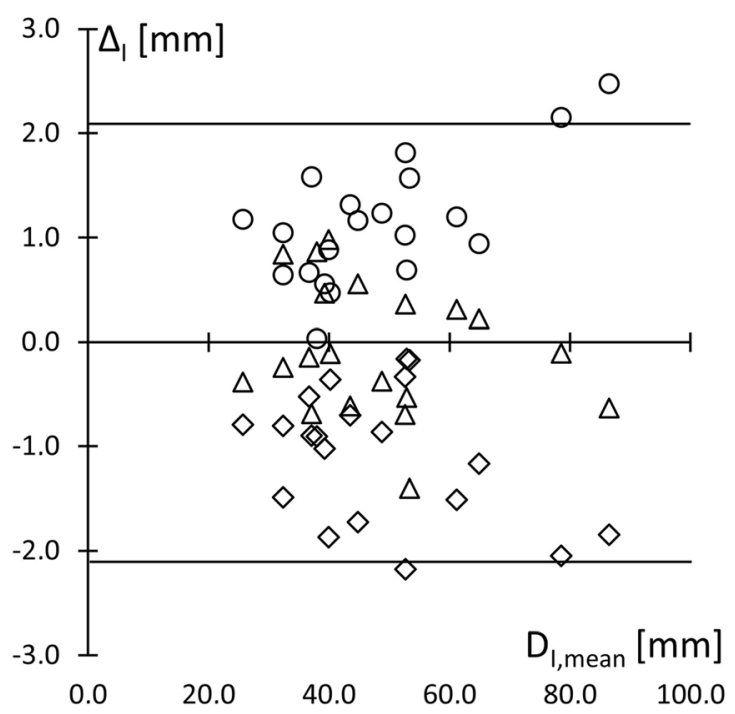

b

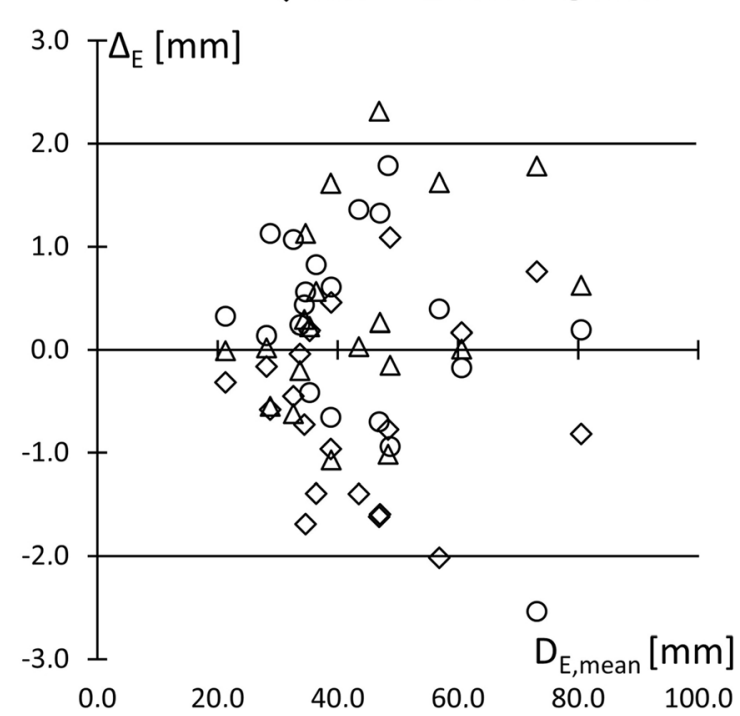

Fig. 3 Observer differences from the mean. Individual observer differences $(\Delta)$ from the mean of the three measurements $\left(D_{\text {MEAN }}\right)$ are shown for each participant (see Table 2). a Individual observer differences from $D_{\text {MEAN }}$ including embedded structures $\left(D_{I, M E A N}\right)$ calculated as $\Delta_{I}=D_{I}-D_{I, M E A N}$ are shown. Standard deviation (SD) of observer differences was $1.1 \mathrm{~mm}, 95 \%$ of the measurements were between $\pm 2.1 \mathrm{~mm}$ (limits of agreement). b Individual observer differences $\Delta_{\mathrm{E}}=D_{\mathrm{I}}-D_{\mathrm{E}, \mathrm{MEAN}}$ are shown. SD of observer differences was $1.0 \mathrm{~mm}, 95 \%$ of measurements were between \pm 2.0 $\mathrm{mm}$ (limits of agreement) 

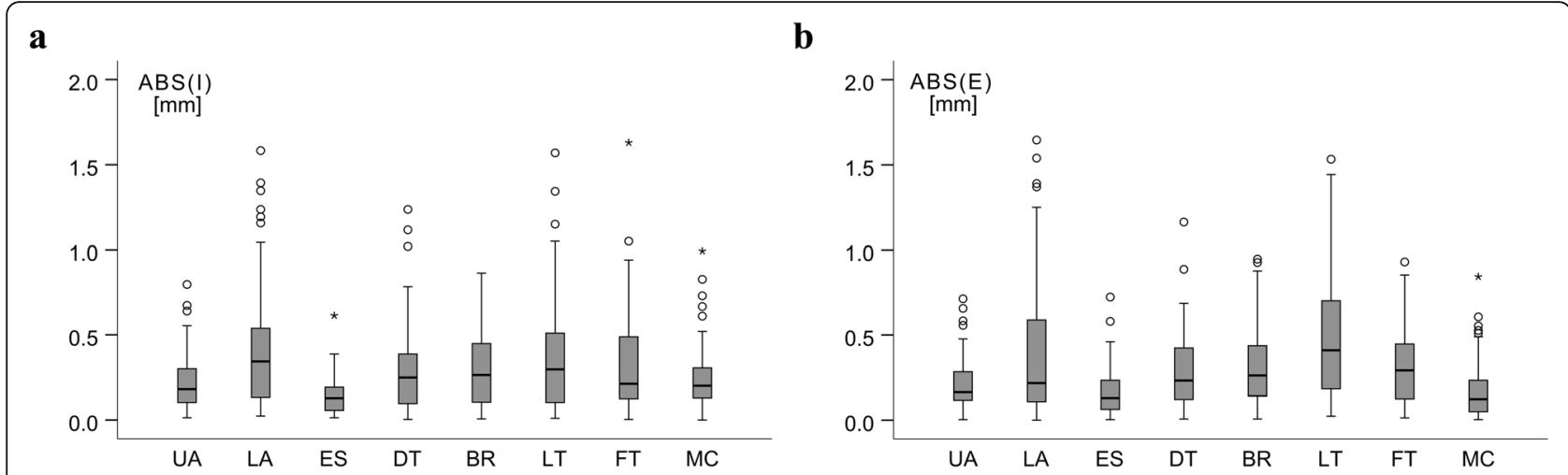

Fig. 4 Absolute measurement differences at the individual sites. Absolute differences $A B S(\delta)$ of each observer from the mean of the three observers were compared at each site $(n=3 \cdot 20=60)$. a ABS $\left(\delta_{1}\right)$ for each of the eight sites including embedded fibrous structures. $\mathbf{b}$ ABS $\left(\delta_{\mathrm{E}}\right)$ for each site excluding embedded fibrous structures. Upper abdomen (UA); lower abdomen (LA); erector spinae (ES); distal triceps (DT); brachioradialis (BR); lateral thigh (LT); front thigh (FT); medial calf (MC). Outliers are shown as circles, extreme values as stars

was $0.8 \mathrm{~mm}$, i.e. about $1.9 \%$ of mean $D_{\mathrm{I}}$. This is comparable to the high reliability that was previously found in adults $[12,19,20]$.

The brightness-mode based ultrasound method for measuring SAT has been standardized [19] and applied to various groups of adults including elite athletes $[12,15,18,19,28]$, patients with anorexia

Table 3 Mean SAT thickness sums and anthropometric characteristics for each participant

\begin{tabular}{|c|c|c|c|c|}
\hline P & $D_{I, \text { MEAN }}[\mathrm{mm}]$ & BMI $\left[\mathrm{kgm}^{-2}\right]$ & $\mathrm{MI}\left[\mathrm{kgm}^{-2}\right]$ & $C[1]$ \\
\hline 1 & 25.7 & 13.6 & 12.5 & 57.6 \\
\hline 2 & 32.4 & 15.3 & 14.7 & 55.0 \\
\hline 3 & 32.4 & 14.7 & 13.8 & 56.3 \\
\hline 4 & 36.7 & 15.2 & 14.1 & 56.9 \\
\hline 5 & 37.1 & 14.7 & 13.6 & 57.1 \\
\hline 6 & 38.0 & 14.2 & 13.6 & 55.4 \\
\hline 7 & 39.2 & 15.4 & 13.8 & 59.2 \\
\hline 8 & 39.9 & 15.7 & 14.5 & 57.2 \\
\hline 9 & 40.2 & 13.8 & 13.0 & 56.2 \\
\hline 10 & 43.5 & 14.5 & 13.5 & 56.9 \\
\hline 11 & 44.8 & 16.7 & 15.6 & 56.7 \\
\hline 12 & 48.7 & 14.2 & 14.0 & 53.7 \\
\hline 13 & 52.6 & 15.4 & 14.7 & 55.5 \\
\hline 14 & 52.7 & 14.7 & 13.5 & 57.4 \\
\hline 15 & 52.9 & 15.6 & 14.7 & 56.3 \\
\hline 16 & 53.4 & 15.6 & 14.8 & 55.8 \\
\hline 17 & 61.2 & 15.7 & 15.0 & 55.3 \\
\hline 18 & 64.9 & 17.7 & 16.5 & 56.6 \\
\hline 19 & 78.5 & 17.5 & 16.5 & 56.2 \\
\hline 20 & 86.4 & 17.7 & 17.1 & 55.0 \\
\hline
\end{tabular}

Mean sum of subcutaneous adipose tissue (SAT) including embedded fibrous structures $\left(D_{\text {IMEAN }}\right)$ shown for each of the 20 participants $(\mathrm{P})$, together with the individual body mass index (BMI), mass index (MI), and Cormic index (C) nervosa [13], and adults with overweight and obesity [20]. Provided that the appropriate speed of sound for adipose tissue is used, accuracy of determining tissue borders is approximately $0.1-0.2 \mathrm{~mm}$ at $12-18 \mathrm{MHz}$ probe frequency $[15,19]$, which cannot be outperformed by any other measurement method due to biological reasons [4].

Previously, this method was used in a pediatric sample for the first time to examine sexual dimorphism of adipose tissue in 274 children aged three to five years. The study found that mean SAT thicknesses significantly differed between boys and girls, even though neither the BMI nor the waist circumference differed [21].

The application of this technique has revealed high intra- and inter-observer reliability in several adult populations [12, 18-20], and high intra-observer reliability in three- to five-year-old children [21]. Table 4 summarizes the results of previous intra- and inter-observer studies comparing the sums of SAT including embedded structures $D_{\mathrm{I}}$ along with the inter-observer results of the present study. This overview shows that differences in $D_{\text {I }}$ were about three times as large when measurements were conducted by novices compared to experienced observers [12]. In this previous publication it was found that $95 \%$ of experienced observer differences from their mean were less than $1.4 \mathrm{~mm}$.

In this sample measured by the three observers, the median absolute value of observer differences in SAT thickness values $\mathrm{ABS}\left(\delta_{\mathrm{I}}\right)$ was $0.3 \mathrm{~mm}$ at each of the sites lower abdomen, lateral thigh, distal triceps, and brachioradialis. However, the medians of the relative values of the differences varied depending on the SAT thickness at the given site: $4.3,2.9,3.4$, and $6 \%$, respectively. The relative differences were smaller with increasing SAT thickness (Fig. 4; Additional file 2). Similarly, Störchle et al. (2017) found absolute differences at the individual sites to increase with increasing SAT 
Table 4 Overview of inter-observer and intra-observer reliability studies results

\begin{tabular}{|c|c|c|c|c|c|}
\hline Study reference & Sample & Observers & $D_{1}$-range $[\mathrm{mm}]$ & $95 \%$ of values $D_{1}[\mathrm{~mm}]$ & Median of $A B S\left(\Delta D_{1}\right)[\mathrm{mm}]$ \\
\hline \multicolumn{6}{|c|}{ Inter-observer studies } \\
\hline (19) & Adults & $\mathrm{EO}$ & $10-51$ & \pm 1.0 & 0.2 \\
\hline (12) & Adults & $\mathrm{EO}$ & $6-70$ & \pm 1.2 & 0.3 \\
\hline (12) & Adults & NO & $6-70$ & \pm 3.1 & 1.0 \\
\hline Current & Children & $\mathrm{EO}$ & $26-86$ & \pm 2.1 & 0.8 \\
\hline \multicolumn{6}{|c|}{ Intra-observer studies } \\
\hline (20) & Adults & EO & $12-77$ & \pm 1.4 & 0.4 \\
\hline (20) & Adults & EO & $44-245$ & \pm 2.9 & 0.9 \\
\hline (20) & Adults & EO & $12-245$ & \pm 2.2 & 0.6 \\
\hline (12) & Adults & EO & $6-70$ & \pm 1.4 & 0.4 \\
\hline (12) & Adults & NO & $6-70$ & \pm 3.1 & 0.6 \\
\hline (21) & Children & $\mathrm{EO}$ & $35-112$ & \pm 2.0 & 0.9 \\
\hline
\end{tabular}

Studies comparing the sums of subcutaneous adipose tissue (SAT) including embedded structures $\left(D_{1}\right)$. Numbers in parentheses refer to the references. EO Experienced observers, NO Novice observers, $A B S$ Absolute value, $\triangle D_{1}$ Differences in the sum of SAT thicknesses from the mean of the three of observers

thickness, yet the relative differences decreased with increasing SAT thickness. This was also observed in the sum of SAT thicknesses in the overweight/obese group with larger SAT thickness sums: median $\Delta_{\mathrm{I}, \mathrm{rel}}=0.5 \%$, compared to the leaner group with median $\Delta_{\mathrm{I} \text {,rel }}=1.1 \%$ [20]. Obviously, both intra- and inter-observer differences increase with larger SAT thickness sums, however, the relative differences decrease with respect to SAT thickness (Table 4).

Although there was a significant correlation between the BMI and $D_{\mathrm{I}}$, a comparison of the BMI and $D_{\mathrm{I}}$ at the individual level revealed substantial differences in SAT thickness sums in several cases, despite a similar BMI (Table 3). For example, two participants who had a difference in BMI of only $0.4 \mathrm{kgm}^{-2}$, showed a difference in $D_{\text {I }}$ of about $29 \mathrm{~mm}: 32.4 \mathrm{~mm}$ versus $61.2 \mathrm{~mm}$. This would result in a prediction error of $90 \%$ if the BMI was used as a measure of fat. This example (and several more ones in Table 3) points out that the BMI should not be used as a measure of an individual's body fat [4].

In addition to its high accuracy and reliability, this method has important advantages that are of particular concern when investigating children: minimal subject involvement, no ionizing radiation is applied, fat thickness layers can be quantified across a wide range of thicknesses, many thickness measurements from one image result in small standard errors of the mean thickness at a given site, and it is applicable in the field.

\section{Limitations}

This ultrasound technique measures SAT, but does not include visceral adipose tissue. However, SAT typically amounts to $80-90 \%$ of total body fat [29-31] and is therefore a good representative of total body fat.
As this is a new approach to analyse body fat in children, normative values for SAT obtained with this highly accurate and reliable US method do not yet exist, but a comprehensive reference data set can now be collated because this research, together with a previous publication [21], have shown that both intra- and interobserver reliability are high and comparable to previous findings in adults.

Guided training of observers is necessary to ensure high accuracy and reliability [12, 19]. For a measurer who had some prior ultrasound imaging experience, a two-day course is sufficient to get started. In this study, experienced observers performed the measurements. For the inter-reliability study this research focused on, the number of measurements was large: three observers captured and evaluated 160 images each; a larger number of participants would not have a noticeable effect on the inter-observer reliability results. However, anthropometric and body composition data of this sample of 20 children is not representative for the statistical population. Future studies in various groups of children will be necessary for deriving normative values based on this standardized measurement technique.

Ultrasound is more expensive than other field methods, but is much cheaper and easier to perform in children than other imaging methods such as magnetic resonance imaging or computer tomography.

\section{Conclusions}

The highly accurate brightness-mode US technique for measuring SAT that has been developed for adults can also be applied to young children aged three to six years: no modification of site definitions was necessary in this group. This standardized method measures uncompressed SAT, which accounts for the most of total body 
fat, on a reliability level comparable to that found in adults previously. Because of the high thickness measurement accuracy (about 0.1 to $0.2 \mathrm{~mm}$ ), this method is the only one that enables a quantification of fibrous structures (fasciae) embedded in the SAT, which amount to a substantial percentage of the subcutaneous adipose tissue mass. The reliability of SAT thickness measurements when embedded fibrous structures (fasciae) are excluded is comparable to the measurements when these structures are included. This standardized method enables body composition and fat patterning analyses in children on a much finer scale than obtainable with any other method. The reliability results found here indicate that there is high potential for ultrasound to replace or compliment other methods for determining body fat in children. Training is necessary to obtain the high reproducibility and accuracy level possible with this standardized method.

\section{Supplementary information}

Supplementary information accompanies this paper at https://doi.org/10. 1186/s12887-020-02044-6.

Additional file 1. SAT thickness sums excluding fibrous structured of each participant measured by the three observers

Additional file 2. Absolute differences in SAT thickness values to the mean of the three measurements at each individual site

\begin{abstract}
Abbreviations
WHO: World Health Organisation; BMI: Body mass index; MI: Mass index; SAT: Subcutaneous adipose tissue; $D_{1}$ : Sum of SAT at eight body sites including embedded fibrous structures; ICC: Intraclass-correlation coefficient; Cl: Confidence interval; $d$ : Mean SAT thickness at a given site; I: Including embedded fibrous structures; E: Excluding embedded fibrous structures; $D_{\mathrm{E}}$ : Sum of SAT at eight body sites including embedded fibrous structures; SD: Standard deviation; $\Delta$ : Difference of the sum of eight sites from the mean of sums measured by three observers; $D_{\text {MEAN }}$ : Mean of sums measured by three observers; ABS: Absolute; $\Delta_{\text {rel: }}$ Relative difference of the sum of eight sites from the mean of sums measured by the three observers; $\varrho$ : Empirical mean deviation in measurements from the three observers for
\end{abstract} each participant at each individual site or each individual sum of SAT

\section{Acknowledgements}

The authors would like to thank all members of the Join the Healthy Boat research group for their input and especially the participating preschool, children and parents.

\section{Authors' contributions}

AK: conception and design of study, data acquisition, analysis and interpretation, drafting of manuscript; WM: conception and design of study, data interpretation, drafting the manuscript; AF: data acquisition, preliminary data analysis, figure layout; MS: data acquisition, preliminary data analysis; HA: review of data analysis and interpretation, and contributions to the manuscript. JMS: study overview, critical revising and finalization of manuscript. All authors read and approved the final manuscript.

\section{Funding}

The preschool-based health promotion program Join the Healthy Boat and its evaluation study are financed by the Baden-Württemberg foundation (grant number BWS 1.479.00 2009), which had no influence on the realization and content of this manuscript.

\section{Availability of data and materials}

All data generated or analyzed during the current study are included in this published article and its' additional files.

\section{Ethics approval and consent to participate}

The Health Survey was registered at the German Clinical Trials Register (DRKS) operated by the German Institute of Medical Documentation and Information, Cologne, Germany (ID: DRKS00010089) and approved by the ethics committee of Ulm University (application number 188/15) and is in accordance with the Declaration of Helsinki. The parents provided written, informed consent for participation in this study, children provided oral assent.

\section{Consent for publication}

Not applicable.

\section{Competing interests}

WM and AF contributed to the software development and may participate in the returns; the other authors have no conflict of interests to declare.

\section{Author details}

${ }^{1}$ Division of Sports and Rehabilitation Medicine, Ulm University Medical Center, Frauensteige 6, Haus 58/33, 89075 Ulm, Germany. ${ }^{2}$ Institute of Biophysics, Medical University of Graz, Neue Stiftingtalstraße 6, 8010 Graz, Graz, Austria.

Received: 26 June 2019 Accepted: 24 March 2020

Published online: 02 April 2020

References

1. Wells JCK, Fewtrell MS. Measuring body composition. Arch Dis Child. 2006; 91(7):612-7.

2. de Onis M, Blössner M, Borghi E, Blossner M, Borghi E. Global prevalence and trends of overweight and obesity among preschool children. Am J Clin Nutr. 2010;92(5):1257-64.

3. UNICEF, WHO, World Bank Group. Levels and trends in child malnutrition: key findings of the 2018 Edition of the Joint Child Malnutrition Estimates; 2018. p. 1-16

4. Ackland TR, Lohman TG, Sundgot-Borgen J, Maughan RJ, Meyer NL, Stewart $A D$, et al. Current status of body composition assessment in sport: review and position statement on behalf of the ad hoc research working group on body composition health and performance, under the auspices of the I.O.C. medical commission. Sport Med. 2012;42(3):227-49.

5. WHO. Physical status: the use and interpretation of anthropometry (WHO technical report series: 854; ISBN 92412085 6) Geneva, Switzerland; 1995.

6. Kagawa M. Anthropometry and health for sport. In: Hume P, Kerr DA, Ackland TR, editors. Best practice protocols for physique assessment in sport. 1st ed. Singapore: Springer; 2018. p. 11-25.

7. Ahrens W, Pigeot I, Pohlabeln H, De Henauw S, Lissner L, Molnár D, et al. Prevalence of overweight and obesity in European children below the age of 10. Int J Obes. 2014;38:99-107.

8. Kurth BM, Rosario AS. Die Verbreitung von Übergewicht und Adipositas bei Kindern und Jugendlichen in Deutschland. Bundesgesundheitsbl. 2007;50: 736-43.

9. Van Stralen MM, Te Velde SJ, Van Nassau F, Brug J, Grammatikaki E, Maes L, et al. Weight status of European preschool children and associations with family demographics and energy balance-related behaviours: a pooled analysis of six European studies. Obes Rev. 2012;13(Suppl 1):29-41.

10. Müller W, Gröschl W, Müller R, Sudi K. Underweight in ski jumping: the solution of the problem. Int J Sport Med. 2006;27(11):926-34.

11. Müller W. Determinants of ski-jump performance and implications for health, safety and fairness. Sport Med. 2009;39(2):85-106.

12. Müller W, Fürhapter-Rieger A, Ahammer H, Lohman TG, Meyer NL, Sardinha $L B$, et al. Relative body weight and standardised brightness-mode ultrasound measurement of subcutaneous fat in athletes: an international multicentre reliability study, under the auspices of the $10 \mathrm{C}$ medical commission. Sport Med. 2020;50:597-614.

13. Lackner S, Mörkl S, Müller W, Fürhapter-Rieger A, Oberascher A, Lehofer M, et al. Novel approaches for the assessment of relative body weight and body fat in diagnosis and treatment of anorexia nervosa: a cross-sectional study. Clin Nutr. 2019;38(6):2913-21. 
14. Marfell-Jones M, Nevill AM, Stewart AD. Anthropometric surrogates for fatness and health. In: Stewart A, Sutton L, editors. Body Composition in Sport Exercise and Health. 1st ed. Abingdon: Routledge; 2012. p. 126-46.

15. Müller W, Horn M, Fürhapter-Rieger A, Kainz P, Kröp JM, Maughan RJ, et al. Body composition in sport : a comparison of a novel ultrasound imaging technique to measure subcutaneous fat tissue compared with skinfold measurement. Br J Sport Med. 2013;47:1028-35.

16. Toomey CM, Cremona A, Hughes K, Norton C, Jakeman P. A review of body composition measurement in the assessment of health. Top Clin Nutr. 2015; 30(1):16-32.

17. Clarys PJ, Martin AD, Drinkwater DT, Marfell-Jones MJ. The skinfold. Mythe and reality J Sports Sci. 1987;5:3-33.

18. Müller W, Horn M, Fürhapter-Rieger A, Kainz P, Kröpfl JM, Ackland TR, et al. Body composition in sport: Interobserver reliability of a novel ultrasound measure of subcutaneous fat tissue. Br J Sports Med. 2013:47(16):1036-43.

19. Müller W, Lohman TG, Stewart AD, Maughan RJ, Meyer NL, Sardinha LB, et al. Subcutaneous fat patterning in athletes: selection of appropriate sites and standardisation of a novel ultrasound measurement technique: ad hoc working group on body composition, health and performance, under the auspices of the IOC medical commission. Br J Sports Med. 2016;50(1):45-54.

20. Störchle P, Müller W, Sengeis M, Ahammer H, Fürhapter-Rieger A, Bachl N, et al. Standardized ultrasound measurement of subcutaneous fat patterning: high reliability and accuracy in groups ranging from lean to obese. Ultrasound Med Biol. 2017;43(2):427-38.

21. Kelso A, Vogel K, Steinacker JM. Ultrasound measurements of subcutaneous adipose tissue thickness show sexual dimorphism in children of three to five years of age. Acta Paediatr. 2019;108(3):514-21.

22. Kobel S, Wartha O, Wirt T, Dreyhaupt J, Lämmle C, Friedemann E-M, et al. Design, implementation, and study protocol of a kindergarten-based health promotion intervention. Biomed Res Int. 2017;2017:4347675.

23. Stewart A, Marfell-Jones M, Olds T, de Ridder H. International standards for anthropometric assessment. Lower Hutt, New Zealand: International Society for the Advancement of Kinanthropometry; 2011.

24. Herman IP. In: Herman IP, editor. Physics of the Human Body. 2nd ed: Springer International Publishing Switzerland; 2016. 661 p.

25. Koo TK, Li MY. A guideline of selecting and reporting intraclass correlation coefficients for reliability research. J Chiropr Med. 2016;15(2):155-63.

26. Bland JM, Altman DG. Statistical methods in medical research. Stat Methods Med Res. 1999:8:135-60.

27. Jones M, Dobson A, Brian SO. A graphical method for assessing agreement with the mean between multiple observers using continuous measures; 2011. p. 1308-13.

28. Kelso A, Trajer E, Machus K, Treff G, Müller W, Steinacker JM. Assessment of subcutaneous adipose tissue using ultrasound in highly trained junior rowers. Eur J Sport Sci. 2017;17(5):576-85.

29. Shen W, Punyanitya M, Silva AM, Chen J, Gallagher D, Sardinha LB, et al. Sexual dimorphism of adipose tissue distribution across the lifespan: a cross-sectional whole-body magnetic resonance imaging study. Nutr Metab (Lond). 2009;6:17.

30. Von Schnurbein J, Klenk J, Galm C, Berg S, Gottmann P, Steinacker JM, et al. Reference values and early determinants of intra-abdominal fat mass in primary school children. Horm Res Paediatr. 2011;75(6):412-22.

31. Ibrahim MM. Subcutaneous and visceral adipose tissue: structural and functional differences. Obes Rev. 2010;11(1):11-8.

\section{Publisher's Note}

Springer Nature remains neutral with regard to jurisdictional claims in published maps and institutional affiliations.

Ready to submit your research? Choose BMC and benefit from:
- fast, convenient online submission
- thorough peer review by experienced researchers in your field
- rapid publication on acceptance
- support for research data, including large and complex data types
- gold Open Access which fosters wider collaboration and increased citations
- maximum visibility for your research: over 100M website views per year
At BMC, research is always in progress.
Learn more biomedcentral.com/submissions

